\title{
Responsividade Materna e Teoria do Apego: Uma Discussão Crítica do Papel de Estudos Transculturais
}

\author{
Adriana F. Paes Ribas ${ }^{12}$ \\ Maria Lucia Seidl de Moura \\ Universidade do Estado do Rio de Janeiro
}

\begin{abstract}
Resumo
A responsividade materna tem sido considerada como um elemento central para a compreensão do desenvolvimento infantil e este conceito tem sido articulado com a teoria do apego. Este artigo tem como objetivo discutir criticamente o papel de estudos transculturais sobre responsividade materna, à luz da teoria do apego, a partir da revisão da literatura recente sobre o tema. Considerando a teoria do apego um referencial valioso para investigações sobre interações mãe-bebê e responsividade materna, as conclusões apontam, basicamente, para três questões: 1) a teoria do apego precisa ser investigada em diferentes contextos socioculturais e receber validação transcultural; 2) pesquisas sobre responsividade materna devem considerar a discussão sobre a teoria do apego e diferenças culturais; 3) a inclusão do estudo da responsividade materna em referenciais teóricos que levem em conta variáveis socioculturais é necessária.

Palavras-chave: Responsividade materna; sensitividade materna; sensitividade; apego; interação mãe-bebê.
\end{abstract}

\section{Maternal Responsiveness and Attachment Theory: A Critical Discussion of the Role of Cross-cultural Studies}

\begin{abstract}
Maternal responsiveness has been considered as an important concept for the understanding of different aspects of infant development, and this concept has been articulated with attachment theory. The objective of this article is to discuss critically the role of transcultural studies about maternal responsiveness, based on attachment theory, and to review of the recent literature about this subject. Considering attachment a valuable theoretical basis for investigations on mother-infant interactions and maternal responsiveness, the conclusions basically point to three issues: 1) the attachment theory needs to be investigated in different sociocultural contexts, to be tested in its limits and to receive a transcultural validation; 2 ) research on maternal responsiveness should take into account the discussion on attachment theory and cultural differences; 3) the inclusion of the study of maternal responsiveness in a theoretical framework that takes into account socio-cultural variables is necessary.

Keywords: Maternal responsiveness; maternal sensitivity; attachment; mother-infant interaction.
\end{abstract}

A responsividade materna tem sido considerada como um elemento central para a compreensão do desenvolvimento infantil em diferentes aspectos (Ex.: cognitivo, emocional, social) e tem sido objeto de muitas investigações (Ex.: Bornstein, 1995; Papoušek \& Von Hofacker, 1998). Como assinalado por Ribas, Seidl de Moura e Ribas (2003) em revisão e discussão crítica sobre este tema, os estudos nessa área têm sido articulados com a teoria do apego. O presente artigo tem como objetivo discutir criticamente o papel de estudos transculturais sobre responsividade materna, à luz da teoria do apego, a partir da revisão da literatura recente sobre o tema.

O conceito de responsividade tem sido estudado mais comumente dentro do referencial da teoria do apego, como discutido em Bretherton (1992) e Ribas e colaboradores (2003). Os trabalhos de Bowlby (1984a, 1984b, 1988) e Ainsworth (1967, 1969, 1989) constituíram a estrutura da teoria do apego, de relevância amplamente reconhecida (Rothbaum, Weiz, Pott,

${ }^{1}$ Este artigo tem origem na tese de doutorado da primeira autora, orientada pela segunda autora, no Programa de Pós-graduação em Psicologia Social da Universidade do Estado do Rio de Janeiro.

${ }^{2}$ Endereço para correspondência: Rua Ferreira Pontes, 286, A, 1007, 20541 280, Andaraí, Rio de Janeiro, RJ.E-mail: aribas@ajato.com.br; mlseidl@alternex.com.br
Miyake \& Morelli, 2000; Waters, Vaugh, Posada \& KondoIkemura, 1995). Uma breve apresentação de algumas de suas idéias centrais e sua relação com o conceito de responsividade mostra-se necessária para a discussão que será apresentada neste artigo.

Ainsworth eBowlby (1991) denominam a teoria originalmente proposta por Bowlby e construída durante 40 anos em colaboração, uma abordagem etológica ao desenvolvimento da personalidade. A teoria do apego foi fortemente influenciada pelos trabalhos de Lorenz (1995) e Tinbergen (1979), e nela é considerado que há uma tendência da espécie para desenvolver relações de apego. Esta característica teria, segundo Bowlby (1984a), uma clara função biológica de sobrevivência da espécie e teria se consolidado no ambiente evolucionário de adaptação.

Nas palavras de Bowlby (1984a): "a função biológica é definida de maneira mais restrita: trata-se daquela conseqüência que, no decorrer da evolução, levou o comportamento em questão a incorporar-se ao equipamento biológico da espécie" (p. 240241).

Segundo Bowlby (1984a), a sobrevivência das crianças, particularmente em uma espécie que precisa do cuidado do outro, depende da manutenção da proximidade de adultos que 
desempenhem funções de proteção e fornecimento de alimentação, conforto e segurança. Integrando conceitos etológicos à sua teoria, esse autor defende que a tendência em estabelecer vínculos com determinados indivíduos é um componente básico da natureza humana, que já está presente ao nascer.

O vínculo, segundo Bowlby (1984a), é um laço relativamente duradouro que se estabelece com um parceiro. O apego é uma disposição para buscar proximidade e contato com uma figura específica, e seu aspecto central é o estabelecimento do senso de segurança. Cabe ressaltar que tanto o vínculo afetivo como o apego são estados internos. Os comportamentos de apego, por sua vez, são observáveis e organizados nas interações das crianças com seus cuidadores, permitindo que a criança consiga ter e manter a proximidade. Tais comportamentos podem ser muito variados, sendo alguns dos mais comuns chorar, chamar, balbuciar, sorrir e agarrar-se.

Para Bowlby (1984a), a ativação destes comportamentos é produto da informação processada por sistemas reguladores de segurança, também chamados sistemas de controle. Este autor distingue quatro sistemas de controle e afirma que, no caso dos sistemas de controle de comportamento de apego, os sensores indicam os seguintes eventos: aqueles que mostram a presença de perigo potencial ou estresse e aqueles relacionados à localização e acessibilidade da figura de apego.

A função deste sistema de controle seria a de garantir que as crianças tenham acesso às pessoas com as quais elas podem obter cuidado e proteção. Como os próprios Ainsworth e Bowlby (1991) assinalam, ambos tinham interesse em conhecer o papel desempenhado pelas interações entre adulto-criança no processo de desenvolvimento das relações de apego. A teoria do apego considera que a qualidade das relações de apego (Ex.: seguro ou inseguro) depende das interações entre a díade mãe-criança.

As discussões de Ainsworth sobre a qualidade do apego se apóiam em observações que ocorriam nas casas das crianças, inicialmente aquelas realizadas em Uganda (Ainsworth, 1967), e em seguida as realizadas em Baltimore. Posteriormente, Ainsworth (ver Ainsworth, Blehar, Waters \& Wall, 1978) desenvolveu a situação estranba, que representa um setting de avaliação estruturado, segundo Cole (1998), para avaliar de forma culturalmente adequada as reações das crianças à separação das mães que havia observado em Uganda. A situação estranha consiste em uma série de episódios nos quais a mãe e a criança são reunidos e separados, envolvendo em alguns deles a presença de uma mulher estranha para a criança. Nesses episódios é observada a reação da criança e, a partir disso, são feitas inferências sobre o tipo de apego que desenvolveu.

Os estudos sobre interação mãe-criança e padrões de apego desenvolvidos dentro deste referencial teórico tratam do conceito de sensitividade ao avaliar os tipos de comportamento específicos da mãe. A concepção de sensitividade mostra-se muito próxima da definição geral de responsividade. Uma análise das definições de responsividade ou sensitividade dentro deste referencial mostra que tanto aparecem as qualificações do tipo calor, proximidade, intimidade, que seriam dimensões avaliativas mais qualitativas e afetivas, quanto a dimensão temporal da contingência da resposta. Bretherton (1992), por exemplo, trata de como as mães respondem apropriadamente, sensitivamente e prontamente aos sinais da criança.

Nas palavras de Bowlby (1988), a saúde mental da criança depende de que ela tenha: “... a vivência de uma relação calorosa, íntima e contínua com sua mãe (ou uma mãe substituta permanente - uma pessoa que desempenha, regular e constantemente, o papel de mãe para ela) na qual ambos encontrem satisfação e prazer"' (p. 13).

Justamente quando se questiona qual a base para a formação do apego é que se evidencia a importância do conceito de responsividade ou sensitividade neste referencial teórico. Segundo esta teoria, a qualidade do apego dependerá da natureza das interações adulto-criança. $\mathrm{O}$ apego seguro, por exemplo, depende da responsividade contingente dos pais em relação ao bebê, ou seja, da capacidade do adulto em mostrar-se sensível às pistas do bebê e responder nos momentos adequados com o sorriso, a fala, etc.

Nos relacionamentos com as crianças, os cuidadores podem expressar diferentes tipos de responsividade eneles os chamados modelos funcionais internos se consolidam. Estes modelos funcionais se estruturam tendo como base elementos como a confiança ou não na figura de apego, o sentimento de rejeição ou afeição, o sentimento de que o outro é ou não uma base segura para exploração do mundo. A natureza dos modelos funcionais, por sua vez, será fundamental para a formação da qualidade do apego.

Deste modo, a responsividade (ou sensitividade) é um dos elementos envolvidos nos primeiros relacionamentos com as figuras de apego, e, portanto, fundamental para a compreensão da qualidade do apego em fases posteriores do desenvolvimento da criança. A qualidade do apego tem sido analisada através do sistema de categorias de Ainsworth (1989) em apego seguro, apego inseguro evitante e apego inseguro ambivalente, neste caso, considerando-se os padrões típicos de apego. Uma classificação que considere também os padrões atípicos de apego deve incluir os seguintes padrões: desorganizado/desorientado, evitante/ ambivalente e instável-evitante (ver Barnett \& Vondra, 1999; Waters \& Valenzuela, 1999, sobre padrões atípicos de apego).

\section{Teoria do apego e estudos transculturais}

Uma questão central de interesse para a pesquisa sobre responsividade materna é a controvérsia sobre a compatibilidade de se utilizar o referencial teórico do apego vinculado às abordagens culturais que investigam responsividade materna e 
outros elementos envolvidos nos sistemas de práticas parentais. Bretherton (1992) entende que é possível esta articulação, inclusive destacando as pesquisas realizadas por Ainsworth em Uganda, argumento também utilizado por Van Ijzendoorn e Sagi (2001) ao afirmarem que desde então a teoria do apego tem sido estudada em sua universalidade e validade transcultural.

Por outro lado, autores como Tronick, Morelli e Ivey (1992) entendem que não há uma compatibilidade em aplicar a teoria do apego para investigações transculturais. Os argumentos destes autores centram-se fundamentalmente em três pontos: o primeiro relaciona-se ao modelo de cuidado, o segundo à figura do cuidador primário (e conseqüentemente ao conceito de monotropia), e o terceiro à influência importante da etologia sobre esta teoria. Para esses autores, a teoria do apego está centrada em um modelo de cuidado e contato contínuo que não representaria a diversidade das práticas parentais e que seria muito restrito. A crítica de Tronick e colaboradores (1992) destaca justamente a variação cultural nas práticas de cuidado e a ênfase na figura do cuidador primário, ressaltando que diferentes sistemas de cuidado, incluindo o de cuidados múltiplos e simultâneos, podem serobservados (Ex.: comunidade Efe, estudada por estes autores).

De fato, na teoria do apego o cuidador primário recebe um destaque especial, na medida em que o apego vai se formar inicialmente em relação a esta figura. Bowlby (1984a) chama de monotropia tal "inclinação da criança para apegarse especialmente a uma figura" (p. 327). Deve-se registrar, no entanto, que para Bowlby (1984a) as crianças dirigem comportamentos de apego também para outras figuras, chamadas figuras subsidiárias de apego. No cerne da estrutura teórica do apego, entretanto, está a figura do cuidador primário e a natureza da primeira relação de apego que se estabelecerá entre esta figura e a criança.

Sobre a crítica do modelo de cuidado deve-se destacar que há na teoria do apego o reconhecimento de que diferentes cuidadores poderiam atuar em função de diferentes costumes. Segundo Bowlby (1988):

Cada comunidade tem suas próprias tradições envolvendo a pessoa que normalmente assume essas funções indispensáveis aos cuidados com a criança. Freqüentemente são os pais que assumem o papel mais importante, mas isto nem sempre acontece. As tradições variam, principalmente quanto na medida em que são aceitáveis substitutos para os pais. (p. 79)

Outra crítica refere-se à vinculação da teoria do apego com a etologia e com a abordagem evolucionária o que, segundo estes autores, reforça a idéia de comportamentos específicos e formas prototípicas de agir. Estes enfoques, ainda na opinião de
Tronick e colaboradores (1992), têm em comum a idéia de que as práticas dos pais e as habilidades sociais das crianças são biologicamente baseadas e realizadas de forma prototípica.

De fato, para a teoria do apego (Bowlby, 1984a) a espécie humana é equipada com sistemas comportamentais que têm a função adaptativa de promover a sobrevivência. Como destaca Bretherton (1992) não só os comportamentos de apego das crianças, bem como os comportamentos interativos de resposta daqueles que cuidam delas, têm a função biológica de garantir o cuidado e a proteção das crianças. A sensitividade é considerada como um evento positivo da interação adultocriança e associada a diversos aspectos adaptativos. Desta forma, pode-se esperar que alguns tipos de resposta sensitiva sejam similares entre culturas.

A crítica sobre a influência da etologia e das teorias evolucionárias sobre a teoria do apego não é compartilhada por muitos autores, inclusive aqueles contrários à aplicação dos princípios considerados universais da teoria do apego em diferentes culturas. O argumento de Van Ijzendoorn e Sagi (2001), por exemplo, é o de que a perspectiva evolucionária trata de uma tendência comportamental adaptativa que se mostra de modo específico dependendo do nicho cultural no qual a criança tem que sobreviver.

Parece que a discussão mais adequada neste ponto seria sobre quais comportamentos sensitivos poderiam ser considerados universais e, portanto, determinados biologicamente, e quais os que dependeriam de influências da cultura. Outra forma de considerar essa questão seria, como o comportamento sensitivo biologicamente programado pode ser expressado de formas diferentes de acordo com a cultura.

Tronick e colaboradores (1992) entendem que a teoria do apego falha pelo fato de não estar sensível ao papel desempenhado pelos fatores ecológicos e socioculturais e em seu poder de dar forma às experiências sociais da criança. Além disso, tem como deficiência ser insensível à influência mútua que pais e as crianças exercem na qualidade de suas trocas sociais.

Umintenso debate tem sido realizado na literatura psicológica atual sobre a questão do apego e da cultura. Rothbaum e colaboradores (2000) são alguns dos mais críticos em relação às diferenças culturais e a teoria do apego. O posicionamento crítico destes autores foi bastante contundente, suscitou a réplica de outros reconhecidos pesquisadores na área do apego, tais como Van Ijzendoorn e Sagi (2001) e Posada e Jacobs (2001), entre outros, e foi seguida dos comentários de Rothbaum, Weiz, Pott, Myake e Morelli (2001).

Rothbaum e colaboradores (2000) consideram a teoria do apego etnocêntrica por ter como base elementos que estão enraizados no pensamento ocidental. Pode-se dizer que o posicionamento desses autores foi bastante crítico na medida em que eles negam a universalidade das três hipóteses centrais 
da teoria do apego, que são as hipóteses da sensitividade, da competência e da base segura. Os autores utilizam observações comparativas realizadas entre Japão e Estados Unidos, e destacam que a teoria do apego requer mudanças fundamentais quando aplicada a culturas não ocidentais.

A discordância dos autores em relação à hipótese da sensitividade é especialmente importante. Rothbaum e colaboradores (2000) entendem que o que Ainsworth (1988) considerava como cuidado sensitivo e responsivo reflete o valor dado na cultura ocidental para a autonomia da criança. Utilizam, estes autores, a escala para avaliação de cuidado, proposta por esta autora, para mostrar o predomínio da valorização da autonomia (Ex.: espera-se que o adulto aceite o bebê como uma pessoa autônoma, separada, que o adulto coopere e evite situações em que tenha que impor suas vontades sobre o bebê e que desenvolva no bebê o sentimento de eficácia). Rothbaum e colaboradores (2000) argumentam que o que constitui um cuidado sensitivo e responsivo reflete os valores e objetivos locais, nativos, que podem diferir de uma sociedade para outra.

O Japão é tomado como exemplo de um grupo cultural que expressa a sensitividade de modo particular e diferente do identificado nos Estados Unidos. De modo geral, Rothbaum e colaboradores (2000) entendem que identificaram na cultura japonesa diferenças básicas nas formas pelas quais a sensitividade é expressada (Ex.: contato prolongado de pele ou formas distais de contato), quando ela ocorre (antecipação das necessidades da criança ou como resposta aos sinais da criança) e nos objetivos dela (acelerar a exploração e autonomia ou a dependência e a proximidade emocional). Estas diferenças centrais revelariam, portanto, uma conceitualização japonesa de sensitividade que difere consideravelmente daquela encontrada na teoria do apego.

Posada e Jacobs (2001) ao discutir o trabalho desses autores comentam que a questão central neste caso deve ser a da hipótese da relação entre sensitividade e segurança e não propriamente as diferentes formas de expressar a sensitividade. Neste sentido, destacam que Rothbaum e colaboradores (2000) não apresentam evidências empíricas que contradigam esta relação.

Gjerde (2001) argumenta que a sensitividade e a competência podem ser definidas em termos locais sem que se quebre a universalidade da teoria do apego. Esta posição também é explicitada por Posada e Jacobs (2001) que entendem que diferenças em como a sensitividade se dá em cada contexto cultural são esperadas.

As argumentações de Posada e Jacobs (2001) e Gjerde (2001) podem ser complementadas pela discussão conduzida por Bornstein (1995) sobre as diferenças nas formas e funções que as atividades parentais podem assumir. Este autor propõe que ao analisar aspectos universais e culturais envolvidos nas interações adulto-criança se considere as formas e as funções dos comportamentos observados. Formas poderiam ser entendidas como as atividades em si, ou seja, os comportamentos. Funções como o significado, a relevância e a interpretação dessas formas. Vinculando a argumentação de Rothbaum e colaboradores (2000) sobre a sensitividade com a proposta de Bornstein (1995) pode-se dizer que a sensitividade, tal como descrita e observada no Japão, em comparação com a observada nos Estados Unidos, seria um exemplo de diferentes formas e diferentes funções.

Por um lado, pode-se assumir que a identificação de padrões e objetivos de sensitividade diferentes não invalidaria a hipótese da sensitividade da teoria do apego, já que se supõe poder haver tais variações, conforme apontam Posada e Jacobs (2001), por exemplo. Por outro lado, cabe questionar se a teoria do apego incluiria em suas categorias de análise da sensitividade elementos diferentes do conceito padrão encontrado na teoria, que se supõe não ser universal.

A discordância de Rothbaum e colaboradores (2000) sobre a hipótese da competência tem como argumento o fato de que a competência social tal como definida na teoria do apego é marcada pelos valores específicos da cultura, sem levar em conta que eles podem ser muito diversos. Destacam neste aspecto que a competência é definida levando em conta aspectos tais como a exploração, autonomia, eficácia, manifestação espontânea de afeto e de desacordo com os pares e sociabilidade com pessoas. $\mathrm{O}$ argumento central é o de que, por exemplo, no Japão o apego seguro não vai levar à sociabilidade com estranhos e que a sociabilidade não tenderá a ser vista como uma forma de competência social. Ilustram com a observação da cultura japonesa como a concepção de competência pode variar substancialmente, envolvendo, por exemplo, a dependência (Ex.: coordenarse com a necessidade do outro), a restrição emocional (Ex.: não expressar ou expressar indiretamente o descontentamento com outra pessoa) e o encorajamento a que as crianças identifiquem pessoas que pertençam ou não ao grupo e evitem pessoas desconhecidas.

A forma como Chen (1996) aborda a questão da dependência vai de encontro à idéia apresentada por Rothbaum e colaboradores (2000), mas parece mais refinada. Este autor destaca que o critério de julgamento japonês sobre como deve ser uma pessoa madura tem relação com a habilidade de ser dependente e que esta habilidade é julgada e também manifestada de maneira sofisticada (Ex.: saber quando, em relação a quem ser dependente e saber quando, como e em relação a quem não ser dependente).

A questão da dependência é analisada por Chen (1996) como estando vinculada com a importância concedida na sociedade japonesa para a tarefa de estar com outros. Na prática parental isto se revelaria pela presença dos pais junto às crianças. Segundo este autor, especialmente em relação às crianças, não é permitido que fiquem desacompanhadas, pois não devem se sentir sozinhas, fato que parece explicar algumas práticas, tais como a intensa 
proximidade física entre mãe e criança, a tendência de carregar no colo crianças de 3 ou 4 anos, o grande número de horas por dia que as mães passam junto aos filhos.

Cabe registrar que na sociedade japonesa, de acordo com Chen (1996), três condições são entendidas como especialmente críticas, nas quais se espera que as crianças estejam possivelmente vulneráveis à solidão: quando separadas do cuidador, quando estão na transição da sonolência para o sono e quando estão no banho.

Uma visão muito crítica em relação às comparações transculturais de padrões de apego é apresentada, ainda, por Rothbaum e colaboradores (2000). Estes autores propõem uma alteração na teoria e nas medidas de apego para que se possa entender o que significa estar seguramente apegado de uma maneira nova, mais diversa e mais relevante do ponto de vista do contexto. Eles destacam que as altas incidências de classificação de crianças na categoria apego inseguro ambivalente no Japão, por exemplo, podem ter relação com as práticas de cuidado e os valores desta cultura. O chamado padrão amae, que caracteriza os relacionamentos entre adultos e crianças no Japão, está próximo dos fatores envolvidos no comportamento ambivalente (Ex.: comportamento pueril, com extrema necessidade de carinho e atenção, agarrar-se muito e buscar proximidade, extrema passividade e falha em se engajar na exploração). Chen (1996) descreve o padrão amae como esperado nas interações entre adultos e crianças, e que tal padrão se mostra como uma tendência do adulto de antecipar o que a criança poderá sentir e buscar se acomodar às suas possíveis necessidades.

A crítica de Posada e Jacobs (2001) é marcada pela consideração de que Rothbaum e colaboradores (2000) negligenciaram muitas pesquisas e que de fato há evidências da universalidade do fenômeno do apego de base segura, e que isto não exclui a existência de diferenças dentro e entre as culturas. Posada e Jacobs (2001) argumentam que há relatos de comportamento de base segura em diferentes culturas, inclusive não ocidentais e não industrializadas citando pesquisa realizada por eles e um grupo de colaboradores em diferentes lugares (Ex.: China, Colômbia, Alemanha, Israel, Noruega e Estados Unidos). O que estes autores argumentam é que encontrar o apego de base segura não significa que as crianças tenham se comportado da mesma maneira em todas as culturas. Destacam que o apego de base segura se deu nos diferentes países de diferentes maneiras, com comportamentos específicos que variaram em função das características individuais e do contexto, mas os autores não discutem que critérios utilizaram nesta avaliação. Permanece ainda, então, a questão destacada anteriormente sobre como a teoria do apego supõe em suas categorias de avaliação da qualidade do apego e da sensitividade materna estas variações comportamentais em função da cultura, tal como descrita por Posada e Jacobs (2001). Essa pergunta é feita também por Lordelo (2002), que indaga sobre vieses culturais na avaliação de responsividade e aponta a necessidade de problematizar esse conceito e suas implicações em termos metodológicos.

O posicionamento de Van Izjendoorn e Sagi (2001) é um dos mais críticos em relação aos argumentos de Rothbaum e colaboradores (2000). Para eles o caso japonês não constitui um falseamento da teoria do apego. Criticam a seleção dos artigos e o enfoque, citando outros trabalhos japoneses que mostram padrões de apego parecidos com aqueles encontrados nos EUA, por exemplo. Van Izjendoorn e Sagi (2001) ressaltam que alguns estudos indicam que o padrão amae de dependência não é o desejado por mães japonesas.

Percebe-se que esta é uma questão controversa, em que não há consenso. Ainda que estes autores sejam contrários ao uso do padrão amae como argumento para esta discussão, Chen (1996), ao analisar a imagem da infância no Japão, destaca o padrão amae como característico da prática parental naquele país. Isto pode revelar tendências de se simplificar a diversidade e complexidade das culturas. Nesse sentido, a tendência a considerar o Japão como comparação com a cultura ocidental e encarar esta cultura como única e homogênea é duramente criticada por Gjerde (2001). Este autor ressalta, inclusive, que este aspecto tem sido estudado por sociólogos e psicólogos no Japão e nos EUA e critica o uso de tais dimensões (Ex.: interdependência, dependência e amae) como base para análise da cultura japonesa.

Finalmente, a terceira hipótese central da qual Rothbaum e colaboradores (2000) discordam é aquela que trata da base segura. Os autores destacam que a consolidação da base segura envolve diferentes comportamentos, sistemas de apego e significados da adaptação, quando são consideradas diferentes culturas.

Posada e Jacobs (2001) criticam a opinião assumida por Rothbaum e colaboradores (2000) argumentando que tanto a teoria do apego, quanto as teorias evolucionárias e as evidências empíricas sugerem que todas as crianças humanas têm o potencial para desenvolver relacionamentos de base segura com um ou poucos cuidadores primários. Entretanto, esta tendência de desenvolver base segura não será sempre explicitada em todas os contextos. A cultura e a família dão forma a como os cuidadores e as crianças se comunicam e usam a base segura em seus relacionamentos.

Rothbaum e colaboradores (2001), ao comentarem as críticas de Van-Ijzendoorn e Sagi (2001) sobre a hipótese da relação entre sensitividade-segurança argumentam que uma pesquisa citada por estes últimos autores é de difícil interpretação já que a correlação relatada entre sensitividade e segurança é muito mais alta do que a correlação média encontrada em uma meta-análise dos estudos ocidentais (realizada pelo próprio Van-Izjendoorn) e muito mais alta do 
que a indicada em outra pesquisa feita no Japão, na qual sequer são encontradas correlações significativas.

Rothbaum e colaboradores (2000) são bastante críticos ao afirmar que a teoria do apego tem deixado em segundo plano o papel da cultura. Consideram que há um número limitado de trabalhos considerando variações culturais e que o foco destes trabalhos está em aspectos periféricos (Ex.: diferença em comportamentos específicos e a incidência de diferentes tipos de apego inseguro) e não questões centrais da teoria como seus antecedentes, conseqüências e a natureza da seqüência do apego. Esta consideração não é compartilhada por Van Izjendoorn e Sagi (2001), por exemplo, que realizaram importantes estudos ${ }^{3}$ na área. Ao discordar das noções centrais da teoria do apego como podendo ser aplicadas a diferentes culturas, Rothbaum e colaboradores (2000) assumem que é impossível manter uma teoria unificada do apego e propõem o desenvolvimento de múltiplas teorias nativas -indigenous theories - sobre apego. Estas novas produções de teoria e pesquisa sobre apego deveriam estar preocupadas com as formas pelas quais o processo de apego está ligado ao contexto cultural no qual ele está inserido. O que é necessário mudar, no ponto de vista de Rothbaum e colaboradores (2000), é a tendência em aceitar como universais humanos elementos da teoria que não têm sido testados suficientemente na diversidade humana.

Os autores supõem que poucos universais sobre o apego vão permanecer e que estes serão limitados a princípios abstratos (Ex.: busca de proximidade e proteção). Muitos dos conceitos centrais do apego, como a sensitividade, a base segura e a competência podem ser de grande valor se assumirem formas mais específicas da cultura. Os autores tentam, assim, acelerar e enriquecer a compreensão do que é culturalmente específico sobre o apego humano e sair de uma teoria unificada para teorias nativas, locais sobre apego.

Chao (2001), ao comentar o artigo de Rothbaum e colaboradores (2000), critica o que chama de um certo entusiasmo ingênuo pelas especificidades culturais, a desconsideração a respeito da generalidade e a proposta de eliminar a teorização. Ressalta que o termo indigenous significa nativo, local, e que os psicólogos que propuseram e que adotam a teoria do apego são, de fato, ocidentais. A autora questiona como se poderia caracterizar o fenômeno do apego se ele variasse em todas as culturas, classes sociais, raças, etc. Aceita a idéia de que uma teoria geral do apego, sensível às diversidades culturais deve ser criada, mas que isto é absolutamente diferente de propor uma variedade de mini-teorias para todas as possíveis variações. Uma teoria do apego sensível à cultura deve, segundo Chao (2001), ser capaz de "descrever processos de apego universais e compreender adequadamente as manifestações específicas da cultura" (p. 823).

\footnotetext{
${ }^{3}$ Uma revisão das pesquisas sobre padrões de apego e situação estranha em diferentes culturas foge aos objetivos deste artigo e, neste sentido, pode-se recomendar o artigo de Van- Ijzendoorn e Kroonenberg (1988).
}

Rothbaum e colaboradores (2001) ao responderem às críticas sobre a proposta de teorias nativas argumentam que o desenvolvimento de teorias nativas não impediria a existência de uma teoria geral do apego. Estas focalizariam a fundo conceitos, práticas e crenças da cultura na qual se estaria estudando este fenômeno, mas deveriam permanecer atentas à teoria existente, neste caso, a teoria original do apego.

Um reconhecimento comum entre diferentes autores, como Bretherton (1992), Van Ijzendoorn e Sagi (2001), Morelli, Tronick e Ivey (1992) é muito bem apresentado por Chao (2001). Tratase da consideração de que a teoria do apego precisa estar aberta para mudanças, para a revisão, para a consideração de aspectos fundamentais relacionados à cultura. Esta abertura não requer descartar a teoria e a metodologia do apego, mas, ao contrário enriquecê-los e ajustá-los para diferentes condições e contextos culturais.

A crítica de Rothbaum e colaboradores (2000) sobre a necessidade de que se questionem, de fato, aspectos centrais da teoria antes de propor comparações transculturais parece muito acertada. Possivelmente este debate tem como cerne a questão da determinação biológica e as variações culturais dos sistemas de apego. Os argumentos de Bornstein (1995) sobre forma e função, apresentados anteriormente, podem ser muito úteis nesta discussão.

Em conseqüência, conceitos-chave como o de responsividade materna, comportamento de apego e as categorias do sistema de apego necessariamente serão re-avaliados. A situação estranha necessita também ser questionada em termos de se de fato é uma medida apropriada de segurança de apego em todas as culturas. Bretherton (1992), por exemplo, entende que a situação estranha e o conceito de sensitividade materna têm validade transcultural em nações industrializadas, mas reconhece que esta questão não está ainda resolvida. Cole (1998) problematiza essa questão e questiona o que se pode inferir dos diferentes padrões de apego observados em diferentes culturas: ou que a situação estranha é um instrumento válido e neutro culturalmente para avaliar uma forma universal de relação, denominada apego; ou que, na verdade, embora padronizada, essa situação tem significados diferentes para os participantes dependendo da cultura a que pertencem.

Em síntese, observa-se que o debate sobre a universalidade da teoria do apego e suas aplicações em diferentes culturas é ainda bastante intenso, como vem sendo explicitado. Bretherton (1992) entende que a teoria do apego pode ser uma estrutura valiosa para examinar as interações entre biologia e cultura e que a pesquisa transcultural pode também colaborar neste sentido. Há 10 anos, essa autora já analisava esta questão de modo muito preciso:

In sum, attachment behavior is heavily overlain with cultural prescriptions... To better explore such cultural variations in 
attachment organization, attachment researchers need to develop ecologically valid, theory-driven measures, tailored to specific cultures and based on a deeper knowledge of parents' and children's culture-specific folk theories about family relationships and attachment. (p. 771)

Apesar das divergências, parece haver um certo consenso (Ex.: Bretherton, 1992; Seifer \& Schiller, 1995; Rothbaum \& colaboradores, 2000; Van Ijzendoorn \& Sagi, 2001) em admitir que a teoria precisa ser investigada em contextos socioculturais diferentes, ser testada nos seus limites e receber uma validação transcultural.

Se por um lado parece necessário avaliar criticamente a aplicação da teoria do apego em investigações sobre responsividade materna, por outro, parece também necessário incluir as investigações sobre este tema em referenciais teóricos que levem em conta elementos da cultura. Neste sentido, pode ser útil articular a discussão conceitual e a investigação empírica sobre responsividade materna à abordagem sociocultural. Este tema é alvo de discussão das autoras em outro artigo (Ribas \& cols., 2003) e está incluído na preocupação geral de busca de articulação entre as perspectivas evolucionária e sociocultural no desenvolvimento inicial.

\section{Considerações Finais}

A teoria do apego permanece como um referencial teórico valioso para as investigações sobre interação adulto-criança e, especialmente, sobre responsividade materna. A análise das controvérsias sobre as aplicações transculturais desta teoria evidencia que essa discussão não a enfraquece. Pelo contrário, aponta para uma tendência de utilização mais cuidadosa e crítica dessa abordagem.

A análise feita leva a que se conclua que a teoria do apego precisa, de fato, ser investigada em diferentes contextos culturais. Por conseqüência, parece necessário cuidado e um posicionamento crítico sobre a utilização da teoria e da metodologia do apego em estudos realizados em diferentes culturas.

O segundo aspecto que se depreende da análise e discussão conduzidas é o da necessidade de que as pesquisas sobre responsividade materna levem em consideração as evidências e os argumentos sobre diferenças culturais e a teoria do apego. Ultrapassando especulações pouco férteis, hipóteses específicas sobre os aspectos universais e culturais (tanto da criança como do adulto) da responvisidade materna devem ser formuladas e submetidas a teste empírico. Para tal, procedimentos metodológicos adequados precisam ser discutidos e analisados.

Por fim, o terceiro ponto refere-se a que a responsividade materna deve ser investigada aliada a referenciais teóricos que levem em conta variáveis socioculturais. Por um lado, esta proposta de aliar o estudo da responsividade à abordagem sociocultural permitiria uma discussão crítica do quanto o que se considera um cuidado responsivo reflete os costumes e práticas de determinado grupo cultural. Por outro lado, propiciaria também uma discussão conceitual sobre responsividade materna, buscando uma definição do conceito que contemplasse ao mesmo tempo propensões possivelmente universais e que incluísse as variações socioculturais. Este trabalho visou dar uma contribuição nesse sentido, dando continuidade a esforços de análise conceitual empreendidos em trabalho recente das autoras (Ribas \& cols., 2003; Seidl de Moura, 2003).

\section{Referências}

Ainsworth, M. D. S. (1967). Infancy in Uganda: Infant care and the growth of love. Retirado em junho, 2002, do SUNY Stony Brook, Department of Psychology Web site: http://www.psychology.sunysb.edu

Ainsworth, M. D. S. (1969). Materna sensitivity scales. Retirado em junho, 2002, do SUNY Stony Brook, Department of Psychology Web site: http:// www.psychology.sunysb.edu

Ainsworth, M. D. S. (1988). On security. Retirado em maio, 2002, da Web site: do SUNY Stony Brook, Department of Psychology Web site: http:// www.psychology.sunysb.edu

Ainsworth, M. D. S. (1989). Attachments beyond infancy. American Psychologist, 44, 709-716.

Ainsworth, M. D. S., Blehar, M. C. Waters, E. \& Wall, S. (1978). Patterns of attachment: A psychological study of the strange situation. New Jersey: Lawrence Erlbaum.

Ainsworth, M. D. S. \& Bowlby, J. (1991). An ethological approach to personality development. American Psychologist, 46, 333-341.

Barnett, D. \& Vondra, J. I. (1999). Atypical patterns of early attachment: Theory, research, and current directions. Monographs of the Society for Research in Child development, 64(3, Serial No. 258)

Bornstein, M. H. (1995). Form and function: Implications for studies of culture and human development. Culture \& Psychology, 1, 123-137.

Bowlby, J. (1984a). Apego. São Paulo: Martins Fontes.

Bowlby, J. (1984b). Separação. São Paulo: Martins Fontes.

Bowlby, J. (1988). Cuidados maternos e saúde mental. São Paulo: Martins Fontes.

Bretherton, I. (1992). The origins of attachment theory: John Bowlby and Mary Ainsworth. Developmental Psychology, 28, 759-775.

Chao, R. (2001). Integrating culture and attachment. American Psychologist, 56, 822 823.

Chen, S. (1996). Positive childishness: Images of childhood in Japan. Em C. P. Hwang, M. E. Lamb \& I. E. Sigel (Orgs.), Images of childhood (pp. 113-128). New Jersey: Lawrence Erlbaum.

Cole, M. (1998). Culture in development. Em M. Woodhead, D. Faukner \& K. Littleton (Orgs.), Cultural words of early childhood (pp. 11-33). London \& New York: Routledge.

Gjerde, P. F. (2001). Attachment, culture, and Amae. American Psychologist, 56, 826827.

Lordelo, E. R. (2002). Interação social e responsividade em ambientes doméstico e de creche: Cultura e desenvolvimento. Estudos de Psicologia, 7, 343-350.

Lorenz, K. (1995). Os fundamentos da etologia. São Paulo: Editora da Universidade de São Paulo.

Papoušek, M. \& Von Hofacker, N. (1998). Persistent crying in early infancy: A non trivial condition of risk for the developing mother-infant relationship. Child: Care, Health and Development, 24, 395-424.

Posada, G. \& Jacobs, A. (2001). Child-mother attachment relationships and culture. American Psychologist, 56, 821-822. 
Ribas, A. F. P., Seidl de Moura, M. L. \& Ribas, R. C. Jr. (2003). Responsividade maternal: Levantamento bibliográfico e discussão conceitual. Psicologia: Reflexão \& Crítica, 16, 137-145.

Rothbaum, F., Weisz, J., Pott, M., Miyake, K. \& Morelli, G. (2000). Attachment and culture: Security in the United States and Japan. American Psychologist, 55, 1093 1104.

Rothbaum, F., Weisz, J., Pott, M., Miyake, K. \& Morelli, G. (2001). Deeper into attachment and culture. American Psychologist, 56, 827-828.

Seidl de Moura, M. L. (2003). O natural e o cultural no desenvolvimento infantil inicial: Uma busca de articulação entre as perspectivas sociocultural e evolucionária (Projeto de pesquisa). Rio de Janeiro: Universidade do Estado do Rio de Janeiro.

Seifer, R. \& Schiller, M. (1995). The role of parenting sensitivity, infant temperament, and dyadic interaction in attachment theory and assessment. Em E. Waters, B. E. Vaughn, G. Posada \& K. Kondo-Ikemura (Orgs.), Caregiving, cultural, and cognitive perspectives on secure-base behavior and working models: New growing points of attachment theory and research (pp. 146-174). Monographs of the Society for Research in Child Development, 60 (Serial No. 244).

Tinbergen, N. (1979). Estudios de etologia. Madrid: Alianza.
Tronick, E. Z., Morelli, G. A. \& Ivey, P. K. (1992). The Efe forager infant and toddler's pattern of social relationships multiple and simultaneous. Developmental Psychology, 28, 568-577.

Van Ijzendoorn, M. \& Sagi, A. (2001). Cultural blindness or selective inattention? American Psychologist, 56 (10), 824-825.

Waters, E. \& Valenzuela, M. (1999). Explaining disorganized attachment: Clues from research on mild-to-moderately undernourished children in Chile. Em J. Solomon \& C. George (Orgs.), Attachment disorganization (pp. 265-290). New York: Guilford Press.

Waters, E., Vaughn, B. E., Posada., G. \& Kondo-Ikemura, K. (Orgs.) (1995). The role of parenting sensitivity, infant temperament, and dyadic interaction in attachment theory and assessment. Monographs of the Society for Research in Child Development, 60 (Serial No. 244).

Sobre as autoras

Adriana F. Paes Ribas é Psicóloga, Doutora em Psicologia Social da Universidade do Estado do Rio de Janeiro. É Professora da Universidade Estácio de Sá. É Pesquisadora integrante do grupo de pesquisa Interação Mãe-bebê e Desenvolvimento, da UERJ.

Maria Lucia Seidl de Moura é Psicóloga, Doutora em Psicologia Cognitiva pela Fundação Getúlio Vargas, Livre-docente pela Universidade Federal do Rio de Janeiro. É Pesquisadora IB do CNPq. É professor titular da Universidade do Estado do Rio de Janeiro, atuando na graduação e no Programa de Pós-graduação em Psicologia Social do Instituto de Psicologia. 